\title{
ЭВДИАЛИТ ЛОВОЗЕРСКОГО ЭВДИАЛИТОВОГО КОМПЛЕКСА
}

\author{
Малыгина А.В., Михайлова Ю.А., Пахомовский Я.А., Базай А.В.Б Калашников А.О. \\ Геологический институт КНЦ РАН, Anamиты, alexaeule@yandex.ru
}

\section{Введение}

Ловозёрский щелочной массив представляет собой подковообразное плато (29×24 км) высотой около 1000 м в западной части Кольского полуострова (рис. 1). Он сложен субгоризонтальными чередующимися слоями нефелиновых сиенитов фойяит-малиньит-шонкинитового ряда и мельтейгит-уртитов. Вся совокупность таких слоёв подразделяется на два комплекса: дифференцированный (внизу) и эвдиалитовый (сверху). В отличие от дифференцированного комплекса мощностью более 2 км, эвдиалитовый комплекс имеет мощность 100-800 м, содержит огромное количество полупереработанных ксенолитов оливиновых базальтов и их туфов, сравнительно слабо дифференцирован и существенно обогащён эвдиалитом (до 80 об. \%) [1, 2].

Минералы группы эвдиалита (МГЭ) являются главными, реже второстепенными породообразующими минералами эвдиалитового комплекса (до 10 об.\% в фойяитах, до 40 об. \% в малиньитах, шонкинитах, ийолитах и мельтейгитах и до 15 об.\% в уртитах). В группу эвдиалита входят сложные цирконо- и титаносиликаты со сложной кристаллохимической формулой:

$$
N(1)_{3} N(2)_{3} N(3)_{3} N(4)_{3} N(5)_{3} M(2)_{3-6} M(3) M(4)\left[M(1)_{6} Z_{3}\left(\mathrm{Si}_{24} \mathrm{O}_{72}\right)\right] O^{\prime}{ }_{4-6} X_{2},
$$

где $N(1-5)=\mathrm{Na}, \mathrm{H}_{3} \mathrm{O}^{+}, \mathrm{K}, \mathrm{Sr}, \mathrm{Ln}, \mathrm{Y}, \mathrm{Ba}, \mathrm{Mn}$ и $\mathrm{Ca} ; M(1)=\mathrm{Ca}, \mathrm{Mn}, \mathrm{Ln}, \mathrm{Na}, \mathrm{Sr}$ и $\mathrm{Fe} ; M(2)=\mathrm{Fe}, \mathrm{Mn}, \mathrm{Na}$, $\mathrm{Zr}, \mathrm{Ta}, \mathrm{Ti}, \mathrm{K}, \mathrm{Ba}$ и $\mathrm{H}_{3} \mathrm{O} ; M(3)$ и $M(4)=\mathrm{Si}, \mathrm{Nb}, \mathrm{Ti}, \mathrm{W}$ и $\mathrm{Na} ; Z=\mathrm{Zr}, \mathrm{Ti}, \mathrm{Nb} ; O^{\prime}=\mathrm{O},(\mathrm{OH})$ и $\mathrm{H}_{2} \mathrm{O} ; X=\mathrm{Cl}$, $\mathrm{F}, \mathrm{H}_{2} \mathrm{O}, \mathrm{OH}, \mathrm{CO}_{3}$ и $\mathrm{SO}_{4}$. Особенностью структуры эвдиалита является одновременное присутствие в каркасе его кристаллической структуры трёх- и девятичленных колец из $\mathrm{SiO}_{4}$-тетраэдров, шестичленных колец из (M1) $\mathrm{O}_{6}$-октаэдров, связанных ребрами, и слоёв, образованных изолированными $Z_{6}$-октаэдрами. В пустотах каркаса располагаются катионы с большими ионными радиусами, а также атомы высокозарядных элементов: кремния, титана, циркония, ниобия и вольфрама $[4,5]$.

\section{Материалы и методика исследования}

В ходе полевых работ 2015-2016 гг. из керна 21 скважины (см. рис. 1) были отобраны 265 координатно-привязанных образцов различных пород. В этих образцах было выполнено 287 микрозондовых анализов состава МГЭ при помощи электроннозондового микроанализатора Сатеса MS-46. Для выявления основных схем изоморфизма в МГЭ применялся факторный анализ, выполненный в программе Statistica-8, а для выяснения закономерности изменения состава рассматриваемых минералов в пределах Аллуйавского участка была построена его 3-мерная минералогическая модель с помощью программы MicroMine 2016.

\section{Результаты}

Результаты микрозондового анализа МГЭ представлены в таблице 1. Кристаллохимические формулы изученных образцов в 38 \% случаев соответствуют манганоэвдиалиту, а в остальных - собственно эвдиалиту. Факторный анализ данных о составе МГЭ (табл. 2) выявил схему сложного гетеровалентного изоморфизма по схеме $(\mathrm{Fe}, \mathrm{Mg})^{2+}+\mathrm{Zr}^{4+}+2 \mathrm{Na}^{+} \leftrightarrow \mathrm{Si}^{4+}+\mathrm{Mn}^{2+}+R E E^{3+}+\mathrm{Nb}^{5+}+(\mathrm{Ca}, \mathrm{Sr})^{2+}$. В результате такого замещения манганоэвдиалит оказался относительно обогащённым $R E E$, тогда как большая часть собственно эвдиалита $-\mathrm{Zr}$ и Al. Второй фактор зафиксировал повышенное содержание Y, Sm и Gd в эвдиалите, относительно обогащённом $\mathrm{Zr}$ и Al, а также преимущественное концентрирование $\mathrm{Ca}$ и $\mathrm{Nb}$ в составе эвдиалита из высококальциевых фойяитов. В наборе редкоземельных элементов преобладают лёгкие лантаноиды: Ce (50 отн. \%), $\mathrm{Nd}(25), \mathrm{La}(23)$ и $\mathrm{Pr}(2),-$ причём возрастание суммарного содержания редкоземельных элементов также происходит, главным образом, за счёт церия и лантана.

В соответствии с основной схемой изоморфизма, на разрезах Аллуайвского участка концентрация Mn и REE в составе МГЭ последовательно увеличивается с глубиной (рис. 2). Наоборот, со- 


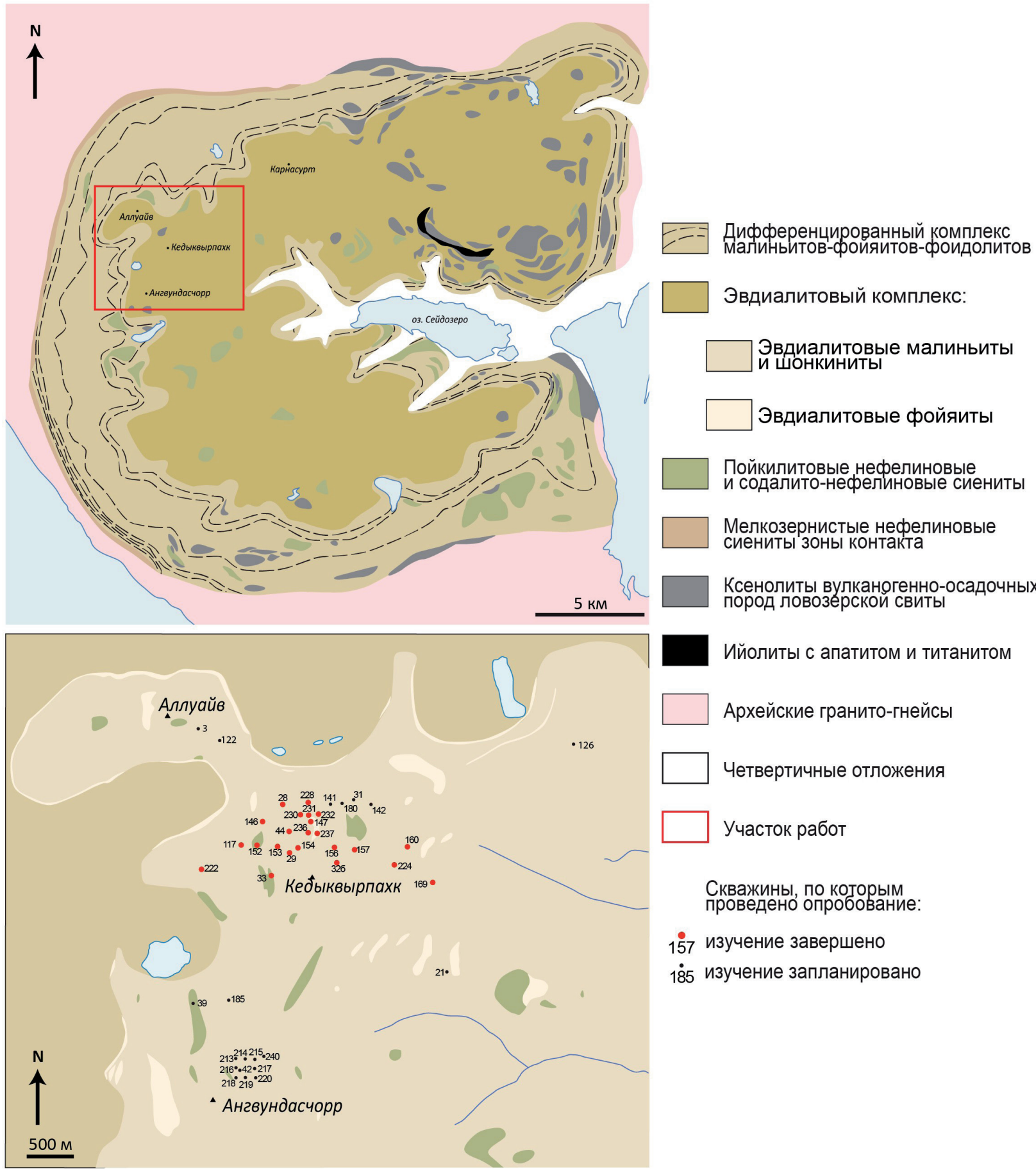

Рис. 1. Схема геологического строения Ловозёрского щелочного массива (по [1] с дополнениями [2]) и Аллуайвского участка Ловозёрского эвдиалитового месторождения [3].

держание $\mathrm{Zr}$ и Fe с глубиной уменьшается (рис. 3), так что с глубины примерно 850 метров манганоэвдиалит стабильно преобладает над эвдиалитом. Зона развития МГЭ с повышенным содержанием Са и $\mathrm{Nb}$ фиксирует пласт лейкократовых высококальциевых фойяитов (фенитизированных метабазальтов) с анортоклазом и диопсидом (рис. 4). Судя по тому, что эвдиалит в этих породах обычно образует каймы вокруг скоплений паракелдышита, можно предположить, что часть эвдиалита образовалась путём замещения первичных безводных цирконосиликатов из-за воздействия высококальциевых флюидов, сформировавшихся в ходе фенитизации оливиновых базальтов и туфов трапповой формации $[2,6,7]$.

Работы проводились при финансовой поддержке Программы 48 Президиума РАН. 
Таблица 1. Химический состав эвдиалита (мас. \%).

\begin{tabular}{|c|c|c|c|c|c|c|c|c|c|c|}
\hline & $\mathrm{n}$ & $\mathrm{Me}$ & $\mathrm{Min}$ & $\mathrm{Max}$ & $\mathrm{SD}$ & & $\mathrm{n}$ & $\mathrm{Me}$ & Min & Max \\
\hline $\mathrm{SiO}_{2}$ & 287 & 50.18 & 45.46 & 54.84 & 1.59 & $\mathrm{~K}_{2} \mathrm{O}$ & 287 & 0.30 & 0.13 & 2.31 \\
\hline $\mathrm{TiO}_{2}$ & 287 & 0.62 & 0.24 & 2.25 & 0.22 & $\mathrm{Nb}_{2} \mathrm{O}_{5}$ & 287 & 0.75 & bd & 3.16 \\
\hline $\mathrm{ZrO}_{2}$ & 287 & 13.17 & 6.47 & 20.69 & 1.65 & $\mathrm{Y}_{2} \mathrm{O}_{3}$ & 287 & 0.04 & bd & 0.84 \\
\hline $\mathrm{Al}_{2} \mathrm{O}_{3}$ & 287 & 0.25 & 0.00 & 3.41 & 0.27 & $\mathrm{La}_{2} \mathrm{O}_{3}$ & 287 & 0.31 & bd & 2.13 \\
\hline $\mathrm{FeO}$ & 287 & 2.79 & 0.28 & 6.62 & 1.04 & $\mathrm{Ce}_{2} \mathrm{O}_{3}$ & 287 & 0.77 & 0.08 & 3.66 \\
\hline $\mathrm{MgO}$ & 287 & 0.05 & bd & 0.85 & 0.09 & $\mathrm{Pr}_{2} \mathrm{O}_{3}$ & 287 & 0.01 & bd & 0.33 \\
\hline $\mathrm{CaO}$ & 287 & 7.67 & 2.96 & 15.66 & 1.57 & $\mathrm{Nd}_{2} \mathrm{O}_{3}$ & 287 & 0.32 & bd & 1.86 \\
\hline $\mathrm{MnO}$ & 287 & 2.64 & 1.41 & 11.33 & 0.80 & $\mathrm{Sm}_{2} \mathrm{O}_{3}$ & 287 & 0.01 & bd & 0.36 \\
\hline $\mathrm{SrO}$ & 287 & 1.92 & 0.00 & 5.59 & 0.84 & $\mathrm{Gd}_{2} \mathrm{O}_{3}$ & 287 & bd & bd & 0.44 \\
\hline $\mathrm{BaO}$ & 287 & 0.15 & 0.00 & 1.04 & 0.20 & $\mathrm{HfO}_{2}$ & 287 & 0.03 & bd & 2.67 \\
\hline $\mathrm{Na} \mathrm{O}_{2}$ & 287 & 13.36 & 3.49 & 18.40 & 3.35 & $\mathrm{Cl}_{2}$ & 287 & 1.34 & bd & 2.85 \\
\hline
\end{tabular}

Таблица 2. Результаты факторного анализа данных о составе эвдиалита.

\begin{tabular}{|c|c|c|c|c|c|}
\hline Компонент & Фактор 1 & Фактор 2 & Компонент & Фактор 1 & Фактор 2 \\
\hline $\mathrm{SiO}_{2}$ & 0.109 & 0.097 & $\mathrm{Nb}_{2} \mathrm{O}_{5}$ & $\mathbf{- 0 . 5 4 1}$ & 0.189 \\
\hline $\mathrm{TiO}_{2}$ & 0.321 & 0.060 & $\mathrm{Y}_{2} \mathrm{O}_{3}$ & 0.197 & 0.156 \\
\hline $\mathrm{ZrO}_{2}$ & $\mathbf{0 . 7 7 7}$ & -0.210 & $\mathrm{La}_{2} \mathrm{O}_{3}$ & -0.127 & 0.793 \\
\hline $\mathrm{Al}_{2} \mathrm{O}_{3}$ & $\mathbf{0 . 6 2 5}$ & 0.047 & $\mathrm{Ce}_{2} \mathrm{O}_{3}$ & 0.020 & $\mathbf{0 . 8 4 4}$ \\
\hline $\mathrm{FeO}$ & 0.336 & -0.431 & $\mathrm{Pr}_{2} \mathrm{O}_{3}$ & 0.046 & 0.148 \\
\hline $\mathrm{MgO}$ & 0.041 & -0.157 & $\mathrm{Nd}_{2} \mathrm{O}_{3}$ & -0.027 & $\mathbf{0 . 5 0 5}$ \\
\hline $\mathrm{CaO}$ & 0.172 & 0.294 & $\mathrm{Sm}_{2} \mathrm{O}_{3}$ & $\mathbf{0 . 5 0 1}$ & -0.030 \\
\hline $\mathrm{MnO}$ & 0.159 & $\mathbf{0 . 8 0 3}$ & $\mathrm{Gd}_{2} \mathrm{O}_{3}$ & $\mathbf{0 . 5 1 0}$ & -0.017 \\
\hline $\mathrm{SrO}$ & $\mathbf{- 0 . 5 0 7}$ & 0.224 & $\mathrm{HfO}_{2}$ & 0.105 & 0.197 \\
\hline $\mathrm{BaO}$ & -0.361 & 0.381 & $\mathrm{Cl}_{2}$ & 0.302 & 0.097 \\
\hline $\mathrm{Na} \mathrm{O}$ & $\mathbf{- 0 . 5 5 6}$ & -0.407 & \multirow{2}{*}{ Вклад в дисперсию, \% } & 14 & 14 \\
\hline $\mathrm{K}_{2} \mathrm{O}$ & 0.274 & 0.071 & & & \\
\hline
\end{tabular}
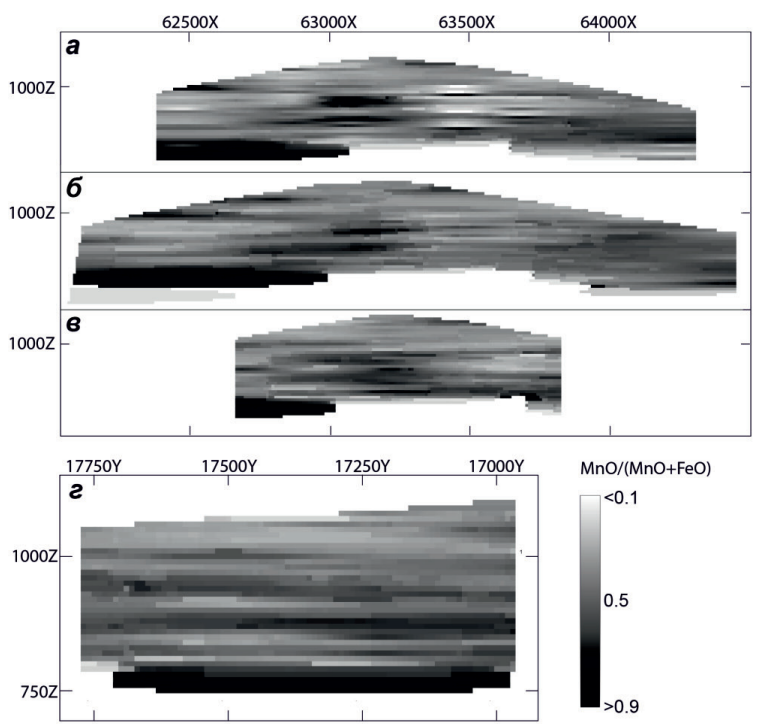
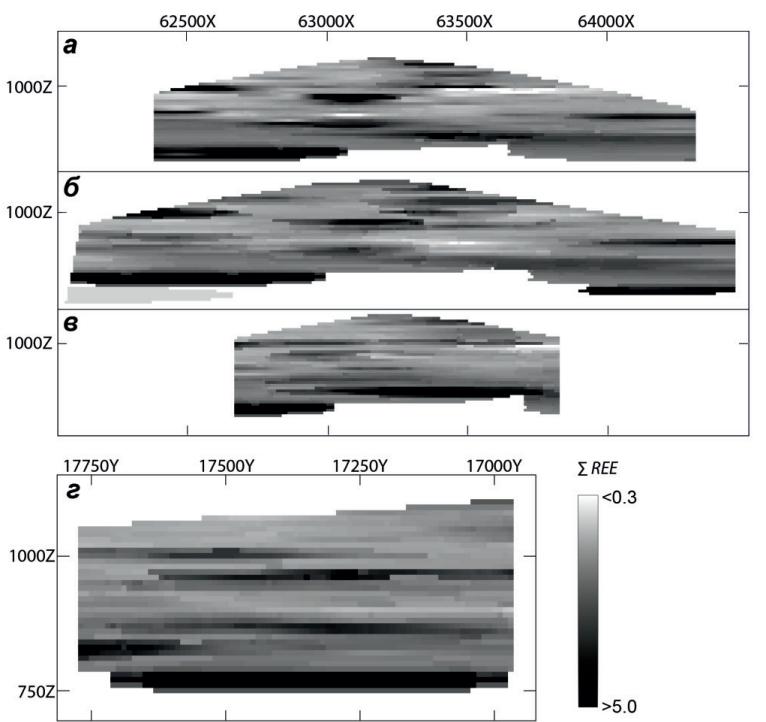

Рис. 2. Вариации соотношения $\mathrm{MnO} /(\mathrm{MnO}+\mathrm{FeO})$ в эвдиалите - слева; вариации суммарного содержания $R E E$ в эвдиалите - справа. а, б, в - разрезы с запада на восток; г-разрез с севера на юг. 


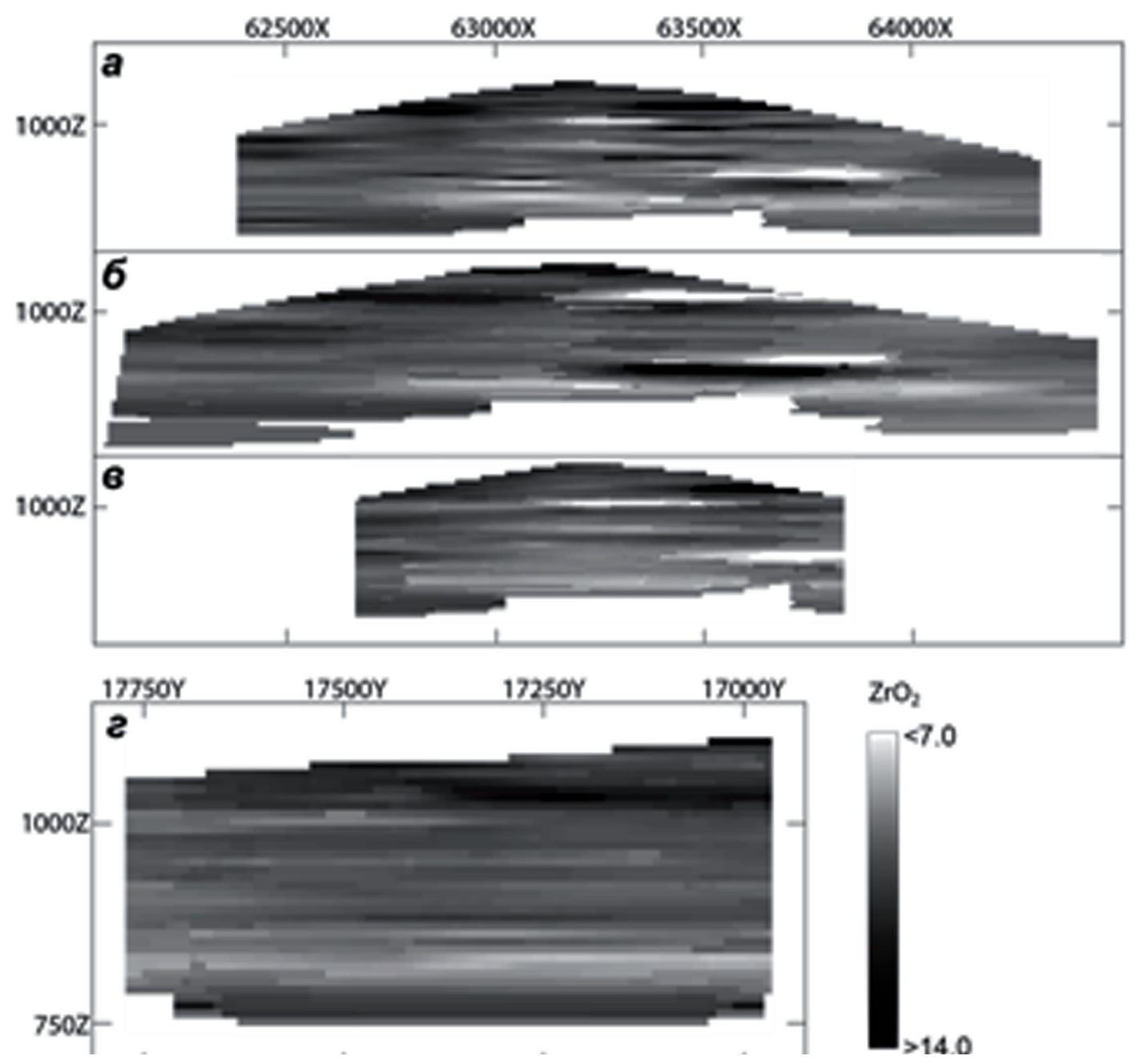

Рис. 3. Вариации содержания $\mathrm{ZrO}_{2}$ в эвдиалите щелочных пород Аллуайвского участка (а, б, в - разрезы с запада на восток; г - разрез с севера на юг)
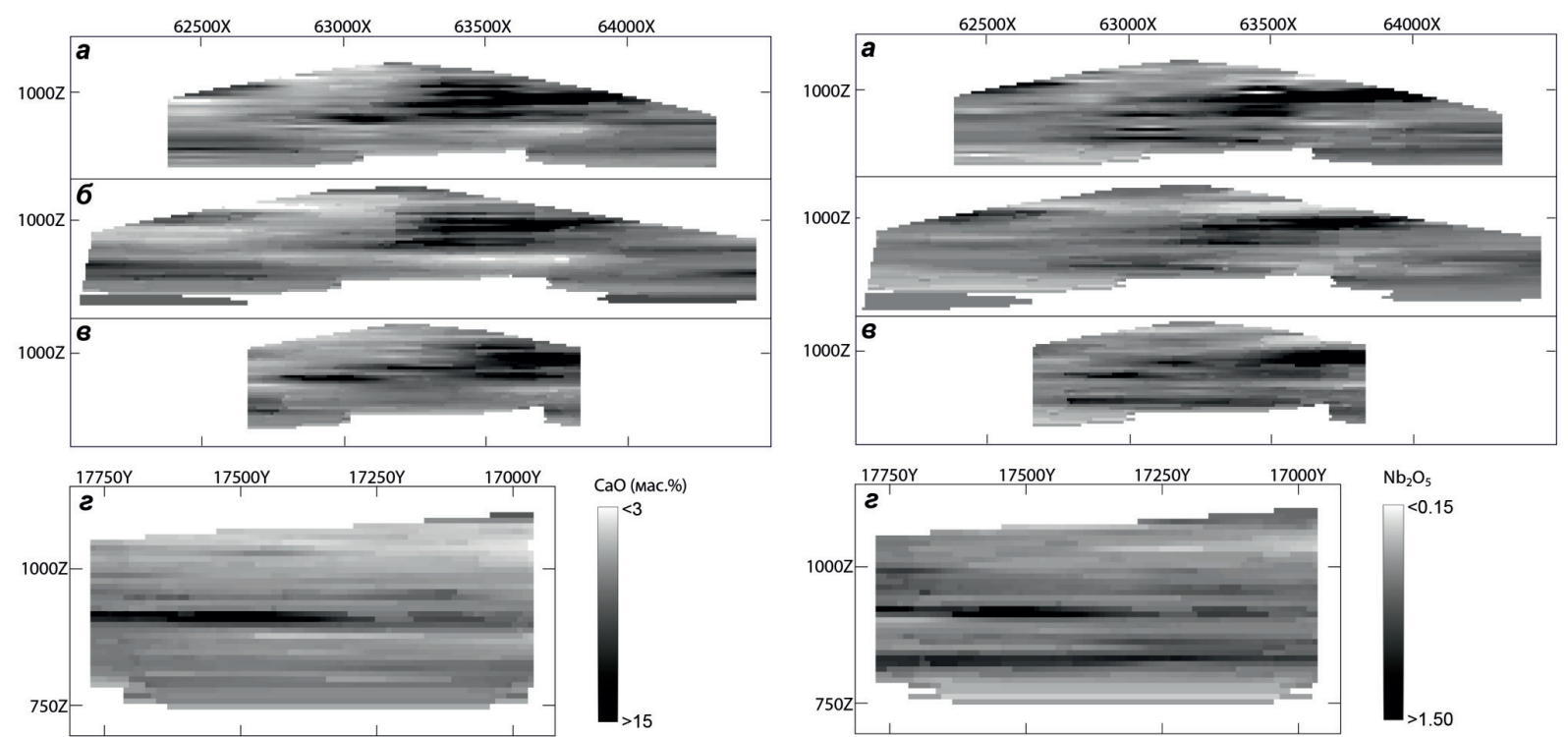

Рис. 4. Вариации содержания оксидов в эвдиалите: $\mathrm{CaO}$ - слева; $\mathrm{Nb}_{2} \mathrm{O}$ - справа (а, б, в - разрезы с запада на восток; г- разрез с севера на юг) 


\section{Литература}

1. Буссен И.В., Сахаров А.С. Петрология Ловозерского щелочного массива. Л.: Наука, 1972. 296 с.

2. Kalashnikov A.O., Konopleva N.G., Pakhomovsky Ya.A., Ivanyuk G.Yu. Rare Earth Deposits of the Murmansk Region, Russia-A Review // Economic Geology, 2016. V. 111. P. 1529-1559.

3. У Укин М.Ю., Сухарев В.Н., Киричек О.П., Уткина Г.А., Лопатин А.С., Кононова Л.Н., Гордиенко А.В., Сайков С., Михаэлис Н.Г. Отчёт о предварительной разведке эвдиалит-лопаритовых и эвдиалитовых руд участка Аллуайв месторождения Чинглусуай в 1989-1992 гг. Кн.1. Ревда. 1995 г. 144 с.

4. Расцветаева Р.К., Чуканов Н.В. Принципы кристаллохимической классификации минералов группы эвдиалита // ЗРМО. 2011. № 3. С. 25-39.

5. Johnsen O., Ferraris G., Gault R., Grice J.D., Kampf A., Pekov I. The nomenclature of eudialyte-group minerals // Can. Mineral. 2003. V. 41. P. 785-794.

6. Korchak Yu.A., Men'shikov Yu.P., Pakhomovskii Ya.A., Yakovenchuk V.N., Ivanyuk G.Yu. Trap Formation of the Kola Peninsula // Petrology. 2011. V. 19. No. 1. P. 87-101.

7. Ivanyuk G.Yu., Pakhomovsky Ya.A., Yakovenchuk V.N. Eudialyte-group minerals in rocks of Lovozero layered complex at Mt. Karnasurt and Mt. Kedykvyrpakhk // Geology of Ore Deposits. 2015. V. 57. No. 7. P. 600-613. 